\title{
PALMERAS, PALMAS Y MIRTOS EN MONEDAS DE COSTA RICA (1825-1951)
}

\author{
José A. VARGAS-ZAMOrA ${ }^{1}$ Y Jorge GÓMEZ-LAURITO ${ }^{1,2}$ \\ ${ }^{1}$ Escuela de Biología, Universidad de Costa Rica, 2060, San José, Costa Rica. \\ ${ }^{2}$ Investigador Asociado. Dept. of Botany, Field Museum of Natural History, Chicago, Il. U.S.A. \\ Autor para correspondencia: javargas@cariari.ucr.ac.cr
}

\begin{abstract}
The coins of Costa Rica include a variety of plant illustrations. The first coin of Costa Rica, a gold half escudo (1825), features a palm tree. Palm branches were frequently used as wreaths in coins. Palm and myrtle (Myrtus communis) branches were also used tied as a wreath encircling the coin value, or under the coat of arms, or both. The palm tree traditionally engraved in many coins since phoenician times is the date palm, Phoenix dactylifera, with attached symbolic attributes like rectitude, strength, and usefulness. The palm branch was a symbol of victory for the greeks and romans. The romans of the first century A.D. associated the date palm with Judea. In this paper we include examples of the use of palm trees of different species, and palm branches, in coins and tokens of Costa Rica and other countries. We also provide examples of the use of the palm branch and the myrtle in coin wreaths.
\end{abstract}

RESUMEN. Las monedas de Costa Rica incluyen una variedad de ilustraciones de plantas. El medio escudo de oro de 1825, incluye una palmera. La palmas fueron frecuentemente grabadas como coronas en monedas. La palma y el mirto (Myrtus communis) también fueron usados como coronas rodeando el valor de la moneda o bajo el escudo de armas, o ambos. La palmera grabada tradicionalmente en monedas desde los fenicios es la datilera, Phoenix dactylifera, a la cual se le atribuyen simbolismos como la rectitud, la firmeza y la utilidad. La palma fue un símbolo de victoria para los griegos y romanos. Los romanos del siglo I D.C. asociaban la palmera con Judea. En este escrito incluimos ejemplos del uso de palmeras de diferentes especies y palmas, en monedas y boletos de Costa Rica y otros países. También damos ejemplos del uso de la palma y el mirto como coronas en monedas.

Palabras ClaVe / Key words: Numismática / munismatics, coins / monedas, Costa Rica, palm tree / palmera, palm branch / palma, Phoenix dactylifera, myrtle / mirto, Myrtus communis.

En nuestros escritos anteriores (Vargas Zamora \& Gómez Laurito 2004, 2005) aportamos información sobre las especies de plantas que fueron grabadas en monedas de Costa Rica en el período 1825-2005. Entre esas especies están algunas de importancia comercial, como el café (Coffea arabica, Rubiaceae), que fue y aún es el principal cultivo en la región central del país, así como el árbol y la flor nacionales (Enterolobium cyclocarpum, Fabaceae, y Guarianthe skinneri, Orchidaceae, respectivamente). Otras especies incluidas en diversas monedas tienen

\footnotetext{
${ }^{1}$ Conferencia impartida en el Auditorio de los Museos del Banco Central de Costa Rica el 9 de marzo del 2006.
}

importancia regional, como la ceiba (Ceiba pentandra, Bombacaceae), o mundial, como las encinas (Quercus spp., Fagaceae). El arte de grabar imágenes de plantas y animales en monedas alcanzó su mejor época en la Grecia de los años 410 a 340 antes de Cristo (A.C.). Las monedas con el búho y una rama de olivo (Olea europaea, Oleaceae) ya identificaban a la ciudad de Atenas alrededor del año 500 A.C. y esa planta era símbolo de victoria (Carson 1962). Aún hoy se otorga una corona hecha con ramas de olivo como premio a los vencedores en los Juegos Olímpicos. El símbolo de la ciudad griega de Metaponto, en el sur de la península itálica, era una espiga de la cebada (Hordeum vulgare, Poaceae), que dividía la moneda en dos partes simé- 
tricas. El laurel europeo (Laurus nobilis, Lauraceae) ya se utilizaba en monedas en el año 400 A.C., en forma de corona para la cabeza de Apolo (Sutherland 1962). La corona de laurel sería adoptada por los emperadores romanos en sus monedas, como las de Claudio y Nerón, así como por numerosos monarcas europeos posteriores. A partir de 1772 los pesos (8 reales) españoles, que también circularon en la Costa Rica colonial, tenían la efigie del monarca adornada con una corona de laurel (Vargas Zamora \& Gómez Laurito 2004). En la colonia fenicia de Cartago, entre los años 410 y 310 A.C. se utilizaron tetradracmas de plata que en una de sus caras tienen grabada una palmera datilera (Phoenix dactylifera, Arecaceae), con un tronco recto, grueso, una docena de palmas, y un par de racimos de dátiles (Carson 1962).

\section{PALMERAS Y PALMAS}

En este escrito utilizamos los términos palmera para referirnos al árbol y palma para la hoja. Aquí ampliamos la información sobre la palmera, que fue grabada en la primera moneda de Costa Rica que data de 1825. De esta pieza (medio escudo, oro de 0.875 milésimas, 1.8 gramos, $16 \mathrm{~mm}$ de diámetro, Fig. 1A) sólo queda alrededor de media docena de ejemplares. Fue acuñada en el Ingenio de Metales de los Horcones, cercano a La Garita, Alajuela, por el ciudadano español Mateo Urandurraga (Murillo 2004). La especie de palmera, que tal vez sirvió de modelo local para la moneda, pudo ser la palma real o corozo (Attalea rostrata, Arecaceae), especie común en esas épocas en los Montes del Aguacate (Vargas Zamora \& Gómez Laurito 2004). Esta palmera fue muy útil para los habitantes del campo y la ciudad, pues sus hojas (palmas) eran el material principal para techar las casas y sus frutos son comestibles (Glassman 1999). El decreto federal emitido en Guatemala en 1824 indicaba que en las monedas de la Federación se debía incluir un árbol como emblema de libertad, al cual se le auguró Libre Crezca Fecundo. Sin embargo, por qué se grabó una palmera en el medio escudo de 1825 sigue siendo una incógnita, aunque tal vez esté relacionado con el simbolismo que esa planta tuvo en tiempos antiguos, según lo indicamos más adelante.
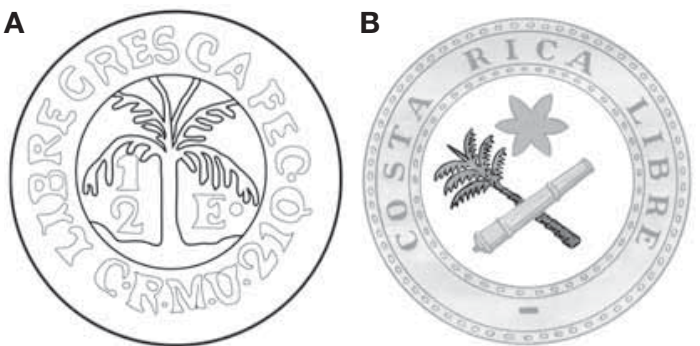

Fig. 1. A. Dibujo de la moneda de medio escudo (1/2 E) del año 1825 con la palmera de seis palmas. Costa Rica (C.R.), Mateo Urandurraga (M.U.), 21 quilates (21 Q). Libre Cresca (sic, crezca) Fecundo. B. Dibujo del sello oficial de 1824 que incluye una palmera con tronco recto y siete palmas (Modificado de Solera Rodríguez 1955).

En un sello del año 1824, cuyo diseño conocemos gracias a que fue copiado de un papel oficial (según Valerio 1940), contiene una palmera cruzada por un cañón y ambos bajo una estrella de seis puntas. En los libros de Solera Rodríguez (1955) y Murillo (2004) se ilustra ese sello, el cual reproducimos en la Fig. 1B. En Pacheco Ureña (2004) se incluye un documento (de Zelaya Goodman 1989) en el cual se contradice la idea de que ese sello corresponde al primer escudo de armas de Costa Rica, tal como se indica en Solera Rodríguez (1955) y Murillo (2004).

El 10 de mayo de 1823 la Junta Gubernativa de Costa Rica había decretado que las monedas de oro y plata deberían tener en el reverso ...una palma en el centro, cruzada por una espada y un fusil con bayoneta, debajo un cañón y entorno la inscripción del valor en pesos o reales que señalase el Gobierno (Solera Rodríguez 1955). Si bien en el Álbum de Figueroa aparece ilustrada una moneda con esas características, hoy no se conoce ningún ejemplar (Chacón Hidalgo 2001). Estas especificaciones difieren de lo que don Mateo grabó en la moneda de medio escudo (Fig. 1A). Lo interesante es que entre 1823 y 1825 había tres diseños (un sello oficial, un decreto de Gobierno y una moneda acuñada por un ciudadano contratado por el Gobierno), que incorporaban una palmera como elemento central. La inclusión de la palmera no fue una idea original de Costa Rica a principios del siglo XIX, pues en América la República de Haití ya hacía unos diez años (1813-1818) que incluía una en 
sus monedas. En Europa también encontramos algunos ejemplos, como en el anverso de un thaler (1808, Sajonia), con dos palmas entrecruzadas (Fig. 2A). Uhlich (1792) menciona que en numismática la palmera es símbolo de firmeza, que proviene de aquellos países conocidos por sus palmeras, como Egipto, Judea, Fenicia y Creta. Otro thaler (Waldeck 1824) tiene una palmera grabada y en la orla la leyenda Palma Sub Pondere Crescit (la palma crece bajo su peso), que le atribuye a esta planta la cualidad de fortaleza. La otra cara incluye dos palmas entrelazadas y semi-cerradas (ver catálogo de Krause \& Mishler 2001: 483). En América, la República de Bolivia grabó, entre 1848 y 1864 (Krause \& Mishler 2001) la palmera Parajubaea torallyi (Palmae), que crece en los valles del centro y sur de ese país, donde es conocida como cocotero de montaña (Moraes 1996). Allí alcanza unos $14 \mathrm{~m}$ de altura y su copa posee unas 20 palmas, curvadas distalmente, tal como se ilustra en la moneda de un peso (Fig. 2B). La fibra de las vainas foliares se usa para hacer cuerdas; los frutos y el corazón del tallo (palmito) son comestibles, lo que la hace muy útil.
A

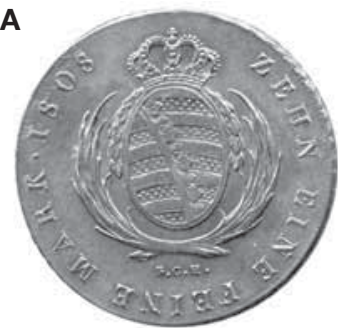

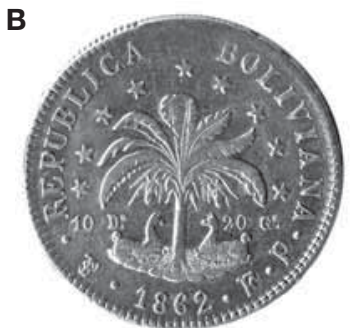

B
Fig. 2. A. Anverso de una moneda de plata (un thaler, Alemania, Sajonia, 1808), con dos palmas cruzadas en la base del escudo. B. Un peso, plata, Bolivia, 1862, con la palmera Parajubaea torallyi.

\section{LA PALMERA DATILERA}

La especie de palmera grabada en varias monedas del mundo es la datilera (Phoenix dactylifera), reconocible ya en monedas fenicias del siglo IV A.C. Desde el final del siglo III A.C. hasta el siglo II después de Cristo (D.C.), la palmera datilera, a veces dibujada con dos racimos de dátiles, fue importante en Fenicia como símbolo de la fecundidad de esa tierra, donde se le asociaba con la ciudad de Tiro (Fine 1989). En esas monedas, la palmera era representada con cinco,
A

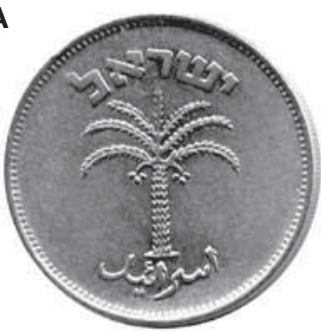

C

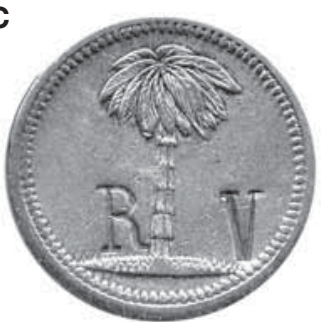

B

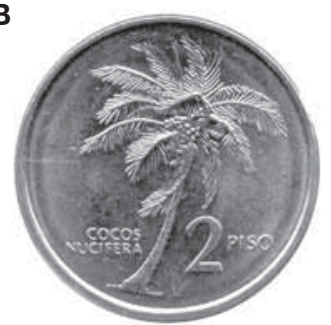

D

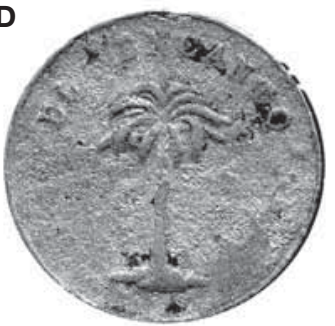

Fig. 3. A. Moneda de Israel, 100 prutah, cupro-níquel, 1955, con la palmera datilera Phoenix dactylifera con siete palmas y dos racimos de dátiles. B. Moneda de 2 piso, acero, Filipinas, con un cocotero, Cocos nucifera. C. Boleto para uso en plantaciones de café de Costa Rica, cobre, $20 \mathrm{~mm}$, contramarcado RV, con una palmera similar al cocotero. D. Boleto de otra finca cafetalera, bronce, $20 \mathrm{~mm}$, con otra palmera similar al cocotero (Colección de Rodolfo Fernández).

siete, o nueve palmas. La palmera grabada en el medio escudo de 1825 tiene seis palmas (Fig. 1A) y siete la dibujada en el sello oficial de 1824 (Fig. 1B). En piezas recientes de Israel se incluye esta especie, con siete palmas (Fig. 3A). Otra palmera interesante en numismática es el cocotero (Cocos nucifera, Arecaceae), como la ilustrada en monedas filipinas recientes (Fig. 3B). Una palmera semejante al cocotero aparece en Costa Rica grabada en algunos boletos usados en plantaciones de café a fines del siglo XIX (Fig. 3 C, D).

La palabra griega Phoenix significa palma y también fenicio o cartaginés (Fine 1989). Desde tiempos bíblicos, la palmera datilera ha sido un recurso natural importante para numerosos pueblos, pues de ella se aprovechan, entre otros: los dátiles para alimento, las hojas en ceremonias, las láminas del tronco para techar casas y las fibras en cestería (Meshorer 2001). Entonces, no es extraño que a través del tiempo esta especie haya sido asociada con virtudes de personas o pueblos. El crecimiento recto del tronco ha servido para representar rectitud en procedimientos. Los griegos utilizaban las palmas 
como símbolo de victoria, pues a Nike, la diosa griega de la victoria, se le representa con una palma en su mano, al igual que a la diosa Victoria de los romanos. En los casos del sello oficial de 1824 y de la primera moneda de Costa Rica, especulamos que la escogencia de una palmera probablemente fue para representar con ésta, de modo similar a lo que se hacía cuando se grababa una palmera datilera, que el joven país (Costa Rica) crecería libre, con fortaleza y rectitud. La riqueza y la utilidad de los recursos naturales de Costa Rica pudieron ser representadas por una palmera.

\section{LA PALMA Y EL MIRTO}

A partir de 1842 y por más de un siglo se acostumbró grabar, en varios tipos de monedas de Costa Rica, una palma entrecruzada en su base con una rama de mirto (Myrtus communis, Myrtaceae). Durante la administración de don Braulio Carrillo (1838-1842) y en ejecución de su decreto del 21 de abril de 1840, se acuñaron monedas, con fecha 1842, de dos tipos: un escudo de

A
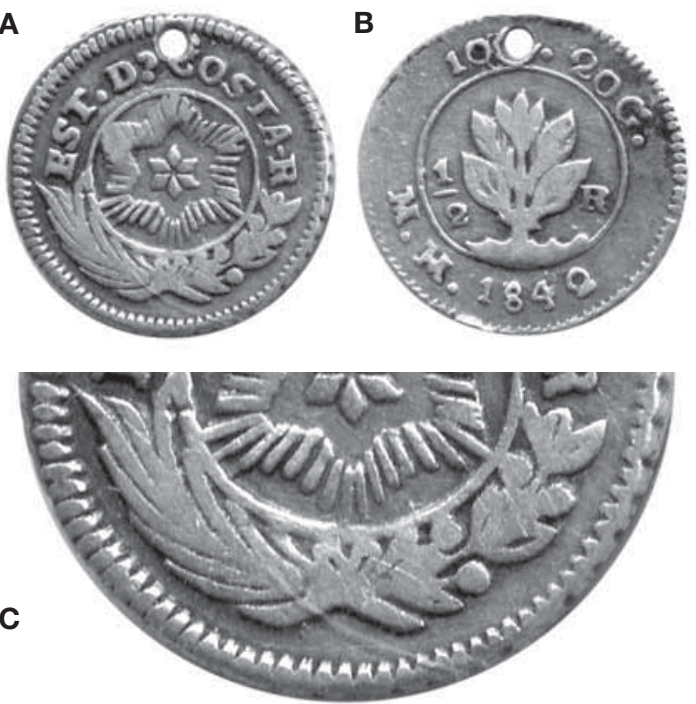

Fig. 4. Anverso (A) y reverso (B) de la moneda de medio real, plata, 1842, $18 \mathrm{~mm}$, Casa de Moneda de San José, Costa Rica. Estrella de Carrillo y planta de tabaco (Nicotiana tabacum). Media corona de palma y mirto bajo la estrella. C. Detalle de la base del anverso mostrando la palma con sus hojuelas separadas y el mirto con sus frutillos pedunculados y hojas opuestas, ovolanceoladas, casi sésiles. oro y un medio real de plata (Gurdián Montealegre 1996). El escudo incluye a la ceiba (Ceiba pentandra) y el medio real a la planta de tabaco (Nicotiana tabacum, Solanaceae). En el anverso de ambas monedas y bajo la estrella de seis puntas (conocida como estrella de Carrillo) están dos ramas entrelazadas, a la izquierda una palma y a la derecha una de mirto. En la Fig. 4A, $B$ ilustramos el anverso y el reverso del medio real de 1842, así como el detalle de la base (Fig. 4C).

En la Grecia antigua el mirto fue consagrado a la diosa Venus y con sus ramas se coronaba a los magistrados atenienses. Además, es símbolo de paz, de gloria y de amor (Vargas Zamora \& Gómez Laurito 2004). Los ejemplos de monedas que incluyen una rama de mirto son abundantes en la numismática mundial, como en la moneda inglesa de seis peniques contramarcada en Costa Rica en 1857 (Fig. 5A, B). De igual modo lo son las monedas que tienen grabada una rama semejante a una palma. El par palma-mirto entrecruzado aparece en varias monedas europeas y americanas, como en la de un sol peruana (Fig. 5C), cuya palma es muy semejante a la grabada en el thaler
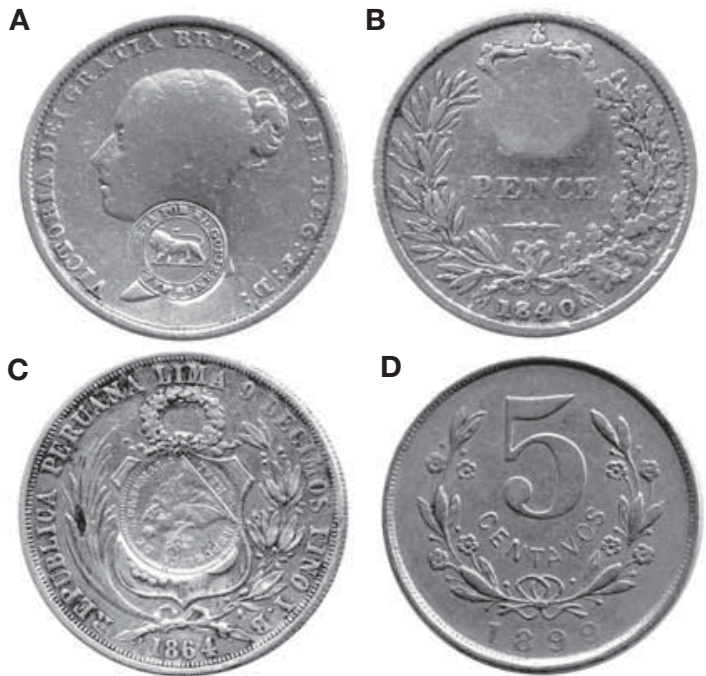

Fig. 5. Anverso (A) y reverso (B) de la moneda inglesa de seis peniques (six pence), plata, 1840, con resello circular con el león pasante y leyenda Habilitada por el Gobierno (de Costa Rica). Ramas de mirto, Myrtus communis (izquierda) y de encina, Quercus sp. (derecha). C. Un sol, plata, Perú, 1864, contramarcado en Guatemala (1894). A los lados del escudo, una palma y una rama similar al mirto. D. Cinco centavos, plata, Nicaragua, 1899. Corona de mirto que incluye varias flores. 
de 1808 (Fig. 2A). El mirto es reconocible por sus frutillos pedunculados, así como por la forma y la posición de las hojas. El grabado de una rama de mirto con sus flores es raro en monedas del mundo, como en la pieza de cinco centavos de Nicaragua, 1899 (Fig. 5D). La flor del mirto es blanca, pentámera, multiestaminada, con sépalos y pétalos libres.

La importancia ceremonial del par mirto-palma es antigua y está mencionada en La Biblia: en Levítico 23:40, dice sobre la Fiesta de los Tabernáculos: el primer día tomaréis hermosos frutos, ramos de palmera, ramas de árboles frondosos, sauces de las riberas, $y$ os regocijaréis durante siete días... En su estudio sobre las monedas de Judea, Meshorer (2001) indica que estas especies son, en el orden citado: el fruto de Citrus medica (Rutaceae) o etrog, la palma de la palmera datilera (P. dactylifera), llamada lulav si tiene sus hojuelas aun sin desplegarse, el mirto (M. communis) con algunos frutos y éstos en número inferior al de

A

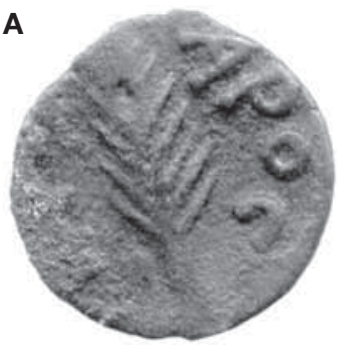

B
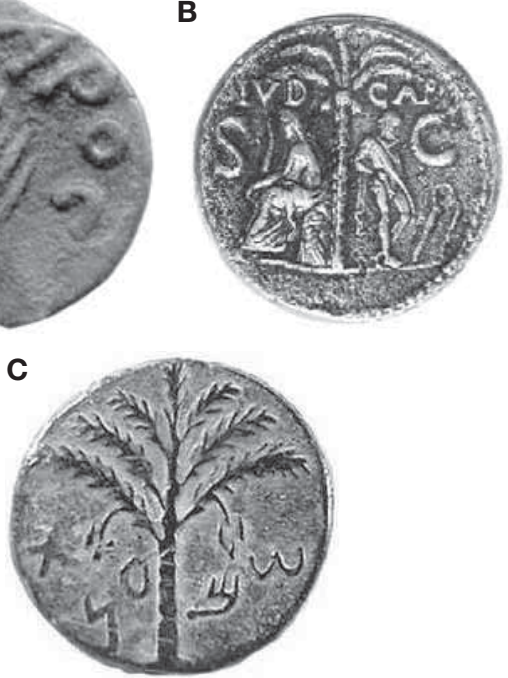

Fig. 6. A. Moneda (lepton) de Judea, bronce, acuñada por el procurador romano Porcius Festus (53-58 D.C.), con una palma de $P$. dactylifera. B. Sestercio, bronce, del emperador Tito (79-81 D.C.) con las letras IVD (Judea), CA (Capta), S C (Senatus Consulto). La cautiva a la izquierda, sentada sobre armas, representa a Judea al igual que la palmera. A la derecha un soldado cautivo con sus manos atadas hacia atrás. C. Moneda de Judea, acuñada durante la rebelión contra los romanos liderada por Simon BarKokhba (113 D.C.), con la palmera datilera que representa a Judea. (B,C, imágenes cortesía del Kadman Numismatic Pavilion, Museo Eretz-Israel, Tel Aviv). hojas. El extremo de la rama de mirto debe estar intacto, como aparece en los grabados de monedas. La última planta puede pertenecer a alguna de las especies del género Salix (Salicaceae, sauces), reconocible por sus hojas elongadas. No es extraño, entonces, que varias monedas antiguas de Judea tengan grabados motivos relacionados con la palmera datilera, como las ilustradas en la Fig. 6 A-C. Para los romanos, la palmera datilera en las monedas pasó a ser el símbolo para identificar Judea, especialmente después del año 70 D.C. (Meshorer 2001).

Con base en la información anterior, podemos deducir que las palmeras ilustradas en monedas de varios países durante más de dos milenios posiblemente tienen por modelo original a la palmera datilera, $P$. dactylife$r a$. En países donde esa especie no es nativa, alguna palmera local similar pudo ser utilizada, preservando a veces el o los simbolismos originales (rectitud, firmeza, utilidad), o agregando alguno más conveniente, como podría haber ocurrido con el medio escudo de Costa Rica de 1825 (Fig. 1A) o con el peso boliviano de 1862 (Fig. 2B). Cuando se grabaron palmas, como en el thaler de 1808 (Fig. 2A), en el medio real de 1842 (Fig. 4A) y en el sol peruano de 1864 (Fig. 5C), se puede argumentar que éstas aluden a la palma de $P$. dactylifera. Muchas ilustraciones de la palma la presentan abierta, como correspondería a su uso como símbolo de victoria, tal vez similares a las usadas para celebrar la entrada de Jesús en Jerusalén (San Juan 12:13, tomaron ramos de palmas y salieron a su encuentro gritando Hosanna!).

\section{CORONAS EN MONEDAS}

En el siglo II A.C. algunas tetradracmas griegas incluían el nombre de la ciudad dentro de una corona hecha con dos ramas entrelazadas (Carson 1962). En Judea, alrededor del año 130 A.C. aparecen monedas con coronas hechas con dos ramas en las cuales alternan hojas y frutos. Las ramas están atadas en su base con una cinta. Este modelo de corona se utilizó en muchas monedas de los siglos XIX y XX. En las monedas de Judea de los años 132 a 135 D.C., las coronas que decoran las inscripciones aparentemente están hechas de olivo, mirto, o palma (Meshorer 2001). En la Fig. 7 A-F incluimos varios ejemplos 
A
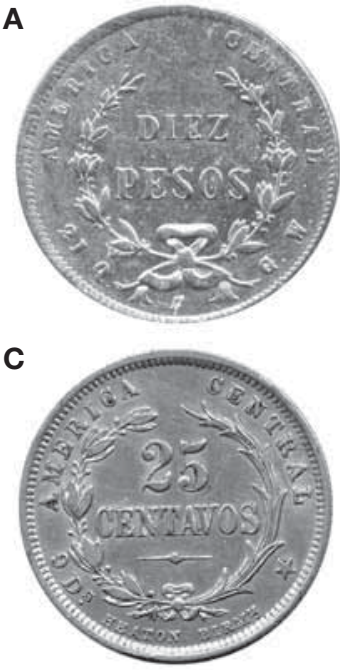

E

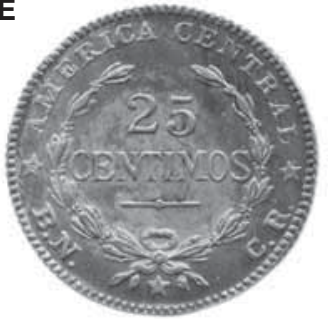

B

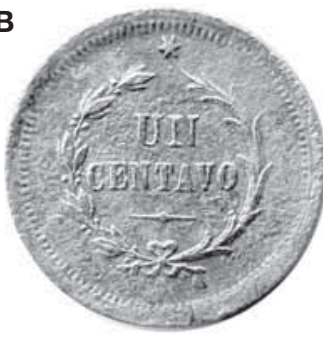

D

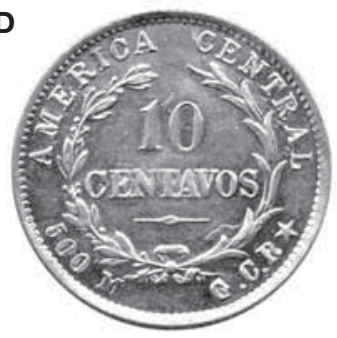

$\mathbf{F}$

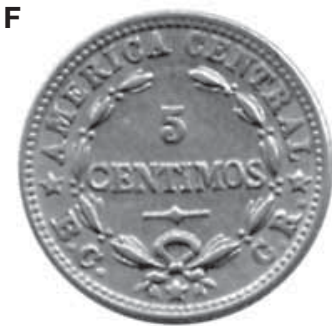

Fig. 7. Reversos de monedas de Costa Rica con coronas atadas en su base con una cinta (1870-1951): A. Diez pesos, oro, 1870, $29 \mathrm{~mm}$, acuñada por la Casa de Moneda de San José. Corona hecha con dos ramas de mirto (M. communis). B. Un centavo, aleación cupro-níquel, 1874, $20 \mathrm{~mm}$, Casa de Moneda de San José. Corona hecha con una palma semi cerrada y una rama de mirto. C. Veinticinco centavos, plata, 1892, 25 mm, acuñada por Heaton, Birmingham, Inglaterra. Corona hecha con ramas de mirto y palma. D. Diez centavos, plata, 1917, Philadelphia Mint, EE.UU. El anverso está incluido en la Fig. 8 D. E. Veinticinco céntimos, latón, 1946, 23 mm, Casa de Moneda de San José. Corona hecha con dos ramas de mirto. F. Cinco céntimos, cupro-níquel, 1951 (tipo 1), 15 mm, Philadelphia Mint, EE.UU. Corona hecha con dos ramas de mirto (última moneda de Costa Rica en que se grabó una corona de mirto).

de coronas grabadas en monedas de Costa Rica. La última moneda de Costa Rica con una corona de mirto fue la de cinco céntimos (Troquel I ) de 1951 (Fig. 7 F). No obstante, a partir de 1935 se empezó a grabar, en las monedas de 25 y 50 céntimos y de un colón, una corona formada por dos ramas (bandolas) de café (Coffea arabica) entrelazadas en su base. Este modelo de corona se utilizó hasta 1995 y luego

su diseño fue modificado de tal modo que las ramas son difíciles de asociar con las de C. arabica en monedas acuñadas posteriormente (Vargas Zamora \& Gómez Laurito 2005).

\section{EL MiRTO EN EL ESCUdO NACIONAL}

El 29 de septiembre de 1848 se emitió el decreto que define el pabellón y el escudo de la República de Costa Rica, así como las especificaciones para las monedas de oro y plata (Lines 1948). El artículo 3 de ese decreto dice: cerrarán el escudo dos palmas de mirto medio cubiertas por un listón ancho que las une, el cual será blanco y contendrá en letras de oro esta leyenda República de Costa Rica. Sin embargo, las palmas de mirto medio cubiertas no serían incorporadas al escudo en las monedas sino hasta 1935. No hemos encontrado información sobre por qué se grabó el par mirto-palma al pie del escudo en varias monedas de plata emitidas entre 1850 y 1893 , o como coronas
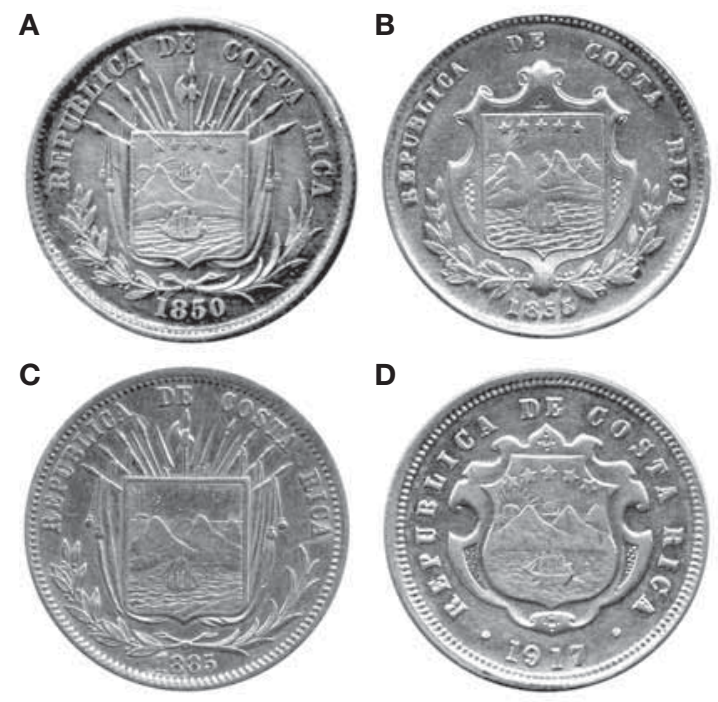

Fig. 8. Anversos de monedas de Costa Rica: A. Un cuarto de peso (1/4 P), plata, 1850, $24 \mathrm{~mm}$, Casa de Moneda de San José. Ramas de mirto ( $M$. communis) y palma entrecruzadas al pie del escudo de armas. B. Dos escudos (2 E), oro, 1855, 23 mm, Casa de Moneda de San José. Dos ramas de mirto en la base del marco del escudo de armas. C. Cincuenta centavos, plata, 1885, $31 \mathrm{~mm}$, Casa de Moneda de San José. Ramas de mirto y palma modificadas levemente. D. Diez centavos, plata,1917, con el tipo de escudo diseñado en 1897, que no incluye el mirto. El reverso está ilustrado en la Fig. 7 D. 
rodeando el valor de la moneda en varias piezas acuñadas entre 1874 (un centavo) y 1947 (diez céntimos). A partir de 1897, se utiliza un nuevo tipo de escudo en las monedas, diseñado por Daniel Wedermann (Murillo 2004), y se suprime el par mirto-palma en la base. Este nuevo escudo está colocado en un marco o cartouche (Wallace 1966), cuyas puntas arrolladas lo asemejan a un pergamino antiguo. Un marco similar fue grabado en las monedas de oro emitidas a partir de 1850. El marco modificado por Wedermann está basado en la forma de escudo conocida como polaca (Valverde Alpízar 2000) y utilizado en monedas desde 1897. En la Fig. 8 (A-C) incluimos ejemplos de anversos de monedas con el tipo de escudo similar al utilizado en monedas españolas (bordes en angulo recto, terminado en punta en su base), y del escudo diseñado en 1897, con bordes curvos y en un marco semejante a un pergamino roto y arrollado (Fig. 8 D).

Agradecimientos. A Cecilia Meir, Museo Eretz Israel, Tel Aviv, por la información sobre monedas de Judea y las imágenes. A Harlan K. Dean por facilitar el acceso a literatura especializada. A Minor Martin por la obtención de varias monedas. A Rodolfo Fernández por el acceso al boleto de la palmera. A Sergio Aguilar por la diagramación del texto y la preparación de las figuras. A Jeffrey Sibaja por el dibujo del medio escudo. Este trabajo está dedicado a la memoria del Prof. José Antonio Vargas Salas (1916-2003), Maestro Normal (1938-1968), agricultor y artesano.

\section{LITERATURA CITADA}

Carson, R.A.G. 1962. Coins of the World. Harper and Brothers Publ., New York. 706 p.

Chacón Hidalgo, M. 2001. José María Figueroa y el aporte al estudio de la historia de las monedas de Costa Rica. Rev. Arch. Nac. 65: 121-137.

Fine, S. 1989. On the development of a symbol: the date palm in Roman Palestine and the Jews. J. Stud.
Pseudepigrapha 4: 105-118.

Glassman, S.F. 1999. A taxonomic treatment of the palm subtribe Attaleinae (tribe Cocoeae). Illinois Biol. Monogr. 59: 1-414.

Gurdián Montealegre, 1996. Contribución al estudio de las monedas de Costa Rica. 2da ed. Litografía e imprenta LIL, San José. 186 p.

Krause, C.L. \& C. Mishler. 2001. Standard Catalogue of World Coins (1801-1900). $3^{\text {rd }}$ ed. Krause Pub. Inc., Iola. $1200 \mathrm{p}$.

Lines, J.A. 1948. Las monedas de oro y plata emitidas por el Dr. Castro. Rev. Arch. Nac. 9/10: 505 - 513.

Meshorer, Y. 2001. A Treasury of Jewish Coins. Yad BenZvi Press, Jerusalem. 356 p.

Moraes, M. 1996. Novelties of the Genera Parajubaea and Syagrus (Palmae) from interandean valleys of Bolivia. Novon 6: 85-92.

Murillo, J. 2004. Historia de las monedas de Costa Rica. Catálogo Numismático. Edit. Universidad Estatal a Distancia, San José. 252 p.

Pacheco Ureña, A.P. 2004. Los Símbolos Nacionales de Costa Rica. Colección de documentos. Imprenta Nacional, San José. 348 p.

Solera Rodríguez, G. 1955. Los Símbolos Nacionales: El Himno, La Bandera, El Escudo. Librería e Imprenta Atenea, San José. 87 p.

Sutherland, C.H.V. 1956. Art in Coinage. The aesthetics of money from Greece to the present day. Philosophical Library, New York. 223 p.

Uhlich, G. 1792. Versuch einer Numismatik für Künstler. Thomas Piller \& U.F. Kaiserer, Lemberg, Wien. 156 p.

Valerio, J. 1940. Informe rendido a la Secretaría de Educación sobre la labor realizada en 1939. Serie de Historia del Museo Vol. 1, Parte II. Imprenta Nacional.

Valverde Alpízar, S.A. 2000. El Escudo Nacional de Costa Rica. Análisis Heráldico. Rev. Acad. Costar. Cienc. Geneal. 38: 477-494.

Vargas Zamora J.A. \& J. Gómez Laurito. 2004. Botánica y Numismática: las plantas en las monedas de Costa Rica (1709-2004). Lankesteriana 4(2): 155-168.

Vargas Zamora J.A. \& J. Gómez Laurito. 2005. Algunas plantas en billetes, boletos de café y cafetales de Costa Rica (1836 - 2004). Lankesteriana 5(2): 141-158.

Wallace, H. 1966. Central American coinage since 1821. Holland Wallace, San Benito, Texas. 125 p. 